\title{
Physikalische Analyse von Lebenserscheinungen der Zelle.
}

II.

\begin{abstract}
Mechanik der Abrückung von Zelleinlagerungen aus Verdichtungscentren der Zelle (im Anschluss an Fischel's Vitalfärbungen von

Echinodermeneierı und Bütschli’s Gelatinespindelı erläutert).
\end{abstract}

Von

\author{
Prof. Dr. L. Rhumbler, \\ Privatdocent und Assistent in Göttingen.
}

Mit 12 Figuren im Text.

Eingegangen am 16. Mai 1899.

\begin{abstract}
"Es ist äberhaupt eine Eigenschaft der entwickelungsmechanischenForschung. dass es meist leichter ist, eine neue Thatsache festzustellen, als ihre Bedeutung richtig zu emitteln; desshalb wird der Sehilderung der Befunde ofteine relativ ausgedehnte Erórterung uher ihre Bedeutung sich anzuschlieben haben.* Roox (Arehiv f. Entwickelungsmech. Bd. I. pag. 16).
\end{abstract}

\section{A. Fischel's Befunde.}

Frscher fürbte in Furchung begriffene Echinodermeneier während des Lebens mit einer äuBerst dünnen Lösung von Neutralroth in Seewasser. Das Neutralroth speicherte sich in kleinen innerhalb des Protoplasmas zerstreut liegenden Körnchen auf, während der Kern und das übrige Protoplasma ungefürbt blieb. Die auf diese Weise durch Rothfärbung deutlich kenntlich gemachten Körnchen zeigten nun während der Furchungsvoryänge sehr bestimmte, offenbar fiir die mechanischen Zelltheilungstheorien höchst benerkenswerthe Verlagerungen.

Sobald die "Cytokinese", d. h. die Gesammterscheinung der während der indirekten Zelltheilung sich im Plasmaköryer der Zelle abspielendén plasmatischen Umlagerungen, beginnt, häufen sich die in der ganzen Zelle allwärts zerstreuten Kömehen in dem 
Centrum der Zelle zusammen und bilden hier eine Hïllkugel um den central gelagerten ungefärbt erseheinenden Kern (Fig. 1). Hier streckt sich dann die Körnerkugel mit der analogen Formveränderung des Kerns zu einem Hüllellipsoid aus (ef. Fig. 2) und wandelt sich

Fig. 1.

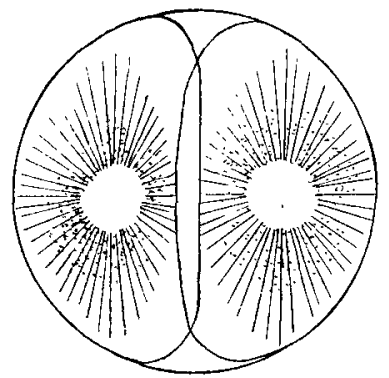

Fig. 2.

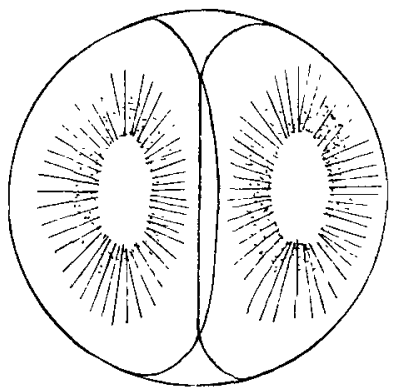

Fig. 1-5. Befruchtetes mit Neutralroth gefäbtes lebendes Ei von Echinus microtubcrculatus während der Bildung der zweiten Farche. Vergr, 300/1. Nach Frschel, 99, Taf. 2425.

Fig. 1. Die Fischel'sehen Körnchen haben sich um die Kerne herum angesammelt.

Fig. 2. Die Kerne und mit ihnen die Zusammenhäufung der Frschec'schen Körnchen strecken sich ellipsoidisch in die Länge.

auch später mit dem Kern in eine Hantelfigur um (Fig. 3). Offenbar hat sich die Körnerkugel dem Kern und seinen beiden Sphären dicht angeschmiegt. 'Die Anschwellungen der Hantel entsprechen

Fig. 3.
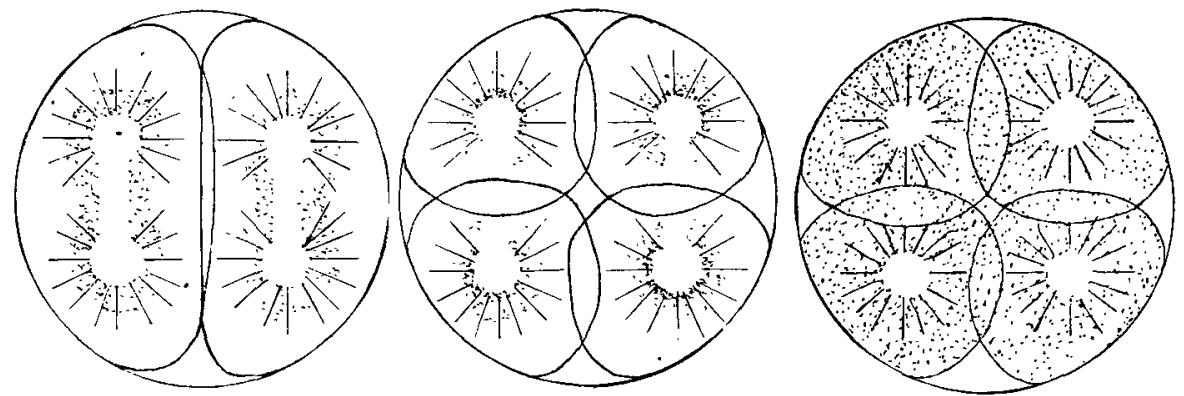

Fig. 3. Kerntheilungsfigur und Kürnchenzusammenhäufung haben IIantelfurm angenommen.

Fig. 4. Die Zellscheidewände sind gebildet, dabei ist die Körnchenzusammenhäufung im Gebiet der Zellscheidewãnde verschwanden.

Fig. 5. Die Tochterzellen sind in das Ruhestadium eingetreten; dabei haben sich die Kürnchen allwärts in den Tochterzellen vertheilt.

den in der Kernpolstellung eingetroffenen Sphären, das Mittelstiuck entspricht der Kernspindel. Wenn nun auf diesem Stadium die Zelldurchschnürung beginnt, verschwinden die Körnchen aus der, der

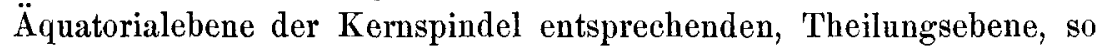
dass jetzt die aus den Körnchen zusammengesetzte Hülle im optischen 
Durchschnitt wie aus zwei geöffneten Ringen, deren öffnung der Theilungsebene zugewendet ist, zusammengesetzt erscheint. (Fig. 4 aus der zweiten Theilung. und Fig. 8 pag. 48, aus der ersten Theilung; letztere besonders klar.) Die Ringe schließen sich damn wieder, während die Zellscheidewand zur Ausbildung kommt, d. h. die Körnchenhûlle ist jetzt zu zwei Kugelhüllen geworden, von denen je eine einen der beiden Tochterkerne einhüllt. Dieses Stadium hält aber nicht an. Sobald die neu entstandenen Blastomeren in das Ruhestadium eintreten, verschwindet die centrale regelmäßige Anhäufung der Körnchen um die Kerne der Tochterzellen (Fig. 5). Sie erfüllen jetzt wieder die ruhenden Tochterzellen ebenso vollständig und regellos, wie sie die ruhende Mutterzelle vor Beginn der Cytodiärese erfüllten. Bei der nächsten Theilung vollzieht sich dann dasselbe Schauspiel wieder.

Hierzu muss noch Folgendes bemerkt werden: bei der Zusammenscharung treten wohl die meisten, aber nicht alle Körnchen in den Umhüllungsmantel des Kernes und seiner Hantel ein. »Die hellgelbe peripherische Zone weist dabei zwar auch einige, aber gegenuiber den um den Kern, angeh:̈uften verschwindend wenige Körnchen auf." Die Körnchenabriickung ron der Theilungsebene erscheint ofter auf der Seite, wo die Durchschnürungsfurche noch nicht sichtbar war oder noch nicht so tief einschnitt, wie auf der anderen Seite der Zelle, zuerst.

Neben Versuchen mit einer größeren Reihe, von anderen Farbstoffen, die keine bemerkenswerthe Resnltate lieferten, muss die Einwirkung ron gleichfalls außerst verdiinntem Bismarckbraun auf die gleichen Objekte angeführt werden.

Dieser Farbstoff wird nicht mit Hilfe von Körnchen sondern diffus von den lebenden Eiem, die er nicht schadigt, angenommen. Die ganze Zelle mit Ausnahme des Kerns färbt sich hellgelb. Diese Fïrbang ist insbesondere während des Ruhestadiums deutlich iuber die ganze Zelle ausgebreitet. Während der Theilung dagegen ist oft der centrale, um den Kern gelegene Abschnitt stärker gefärbt als der peripherische. Die umgebende Farblösung selbst wird nach einiger Zeit völlig entfürbt.

\section{B. Erklärung der Fischel'schen Befunde nach meiner Theorie.}

Die von Fischel beobachteten Erscheinungen werden in der Beantwortung dreier Fragen ihre Erklärung finden. 
Erstens: warum 1) sammeln sich die Körnchen zu Beginn der Cytokinese um den Kern und um seine Sphären herum an?

Zweitens: warum rücken die Körnchen bei Bildung der Zellscheidewand aus der Spindeläquatorebene fort?

Drittens: warum vertheilen sich die Kömchen beim Übertritt in das Ruhestadium wieder allwärts in der Zelle?

\section{Wárum sammeln sich die Körnchen zu Beginn der Cytokinese um den Keun und um seine Sphären herum an?}

Zur Beantwortung dieser muserer ersten Frage sind zunächst drei Möglichkeiten in Betracht zu ziehen. Entweder wandern die FrscireL'schen Körnchen erstens aktiv mit Hilfe eines ihnen innewohnenden Mechanismus von selber nach dem Kern und seinen Sphären hin, oder sie werden zweitens durch Bewegungen des Medinms, in welchem sie eingebettet sind, passiv dahin gebracht, oder es findet drittens ein aktives Hinwandern und passives Hingetragenwerden gleichzeitig statt. Die dritte Annahme bleibt nur dann als walurscheinlich diskutirbar, wenn die erste und zweite Annahme als wahrscheinlich crwiesen sind, sie fällt dagegen als unwahrscheinlich, wenn sich nur eine der beiden ersten Annahmen als wahrscheinlich, die andere aber als unwahrscheinlich erweist. Das mag zur Vermeidung späterer Weitliaufigkeiten gleich hier bemerkt werden.

\section{a. Beruht die Zusammenscharung der Körnchen auf aktiver Wanderung?}

Bei Körperehen von so geringer Größe wie die Fischen'schen Körnchen stellen sich Bewegungsmöglichkeiten ein, - wie Fiscirc hervorhebt - die für größere Körper nicht gelten. Sie zittern bekanntlich unter gegeigneten Bedingungen in sogenannter "BRownscher Molekularbewegung c hin und her, ohne dass sich äußere bewegende Einflüsse bis jetzt bei dieser Bewegung mit Bestimmtheit hätten nachweisen lassen. Größere Körper thun das nicht.

Der Ausdruck »Molekularbewegung* stammt von dem früheren Irrthum her, dass man hier die Bewegung oder die sekundäre Wirkung schwingender Moleküle vor sich habe. Die in »Brown'scher Molekularbewegung « befindlichen, mit dem Mikroskop sichtbaren

1) Warum heißt hier nicht: $s u$ welchem Zweck , sondern sauf Grund welcher Mechanikc. 
Körperchen überragen aber natiirlich jederzeit ebenso wie die FischeLschen Körnchen wirkliche Moleküle noch himmelweit an Ausdehnung. [Für sie können daher auch von voru herein alle »wirklichen "Molekularbewegungen - im Gegensatz zur fälschlich als solche bezeichneten *BRown'schen Molekularbewegung " - als ausgeschlossen gelten. Es ist selbstredend, dass die mikroskopisch sichtbaren FischeL'schen Kürnchen nicht etwa mit wandernden Molekülen oder Molekülgruppen - mit den Ionen der physikalischen Chemie etwa - gleichgesetzt oder nur verglichen werden können. Die große Zahl von Bewegungsmöglichkeiten und Bewegungsgesetzen, die für Moleküle und Molekülgrüße gelten, sind unseren FischeL'schen Körnchen ebenso verschlossen wie anderen größeren Körpern; denn sie sind keine Moleküle.] Die Brown'sche Bewegung ist die einzige Bewegungsart, die sie bei Lageveränderungen vor größeren Körpern unter bestimmten Bedingungen voraus haben könnten.

Wenn also Fischel (99, pag. 501) meint, dass seinen Körnchen als mikroskopisch kleinen, im Plasma suspendirten Elementen an sich schon eine stetige Bewegung zukomme, so wird er wohl dabei an die Brow'sche Molekularbewegung gedacht haben.

\section{«. Beruht die Bewegung der Fischel'schen Körnchen auf Brown'scher Molekularbewegung?}

Kleine Körperchen, die in der BRows'schen Molekularbewegung begriffen sind, schwingen zitternd hin und her. Das geniigt aber zur Erklärung der Zusammenscharung der Fischec'schen Körnchen nicht. Die Bewegung darf keine beliebige, nach allen Richtungen hin wechselnde und pendelnde Bewegung, sondern sie muss eine ihrer Richtung nach bestimmte sein; sonst könnten sich die Körperchen nirgends, also auch um den Kern nicht besonders anhäufen. Bestimmt gerichtete aktive Brow'sche Molekularbewegung kennen wir nicht. Finden irgendwo Zusammenhäufungen von in Brows'scher Bewegung sehwingenden Körperchen statt, so werden diese immer auf passive Weise durch Bewegungen des Einbettungsmediums; nicht aber aktiv von den Körperehen selbst ausgeführt; z. B. durch lokal beschränkte Verdunstungen oder durch Strömungen, die in Folge von lokalen Temperaturdifferenzen im Einbettungsmedium entstehen. Die BRow'sche Bewegung tritt also in solchen Fallen nicht als bewegende Kraft auf, sondern ist eine ganz nebensächliche Begleiterscheinung. Hier aber handelt es sich darum, ob wir die Brown'sche Bewegung selbst als die Bewegungsquelle für die 
Körnchenverlagerung im Echinidenei ansehen dürfen. Das können wir entschieden nicht.

Auch elektrische Erscheinungen sind bei Zelltheilungsvorgängen schon zu oft ausgeschlossen worden, um sie bei der Bewegung der FischeL'schen Körnchen für wahrscheinlich halten za können.

3. Beruht die Bewegung der Fischel'schen Körnchen auf chemotaktischen Vorgängen?

Nach Ausschluss der BRows'sclıen Molekularbewegung könnte man zunächst an chemotaktische Erscheinungen denken.

Auch eine derartige auf Chemotaxis gegründete Erklärung der Kürnchenverlagerung scheint mir aber absolut ausgeschlossen. Man darf Eins bei der Chemotaxis nie vergessen, - das kann nicht oft genug betont werden - dass die Chemotaxis nämlich selbst keine anziehende, dem Magnetismus etwa vergleichbare Kraft, darstellt, sondern dass das Chemotaktikum nur die Auslösungsmittel dafür enthält, dass die Bewegungsorgane einer lebenden Zelle sich in einer zu dem Chemotaktikum hinführenden Weise in Gang setzen; und wenn auch, wie ich schon anderwärts aus einander zu setzen versucht habe, die Auslösung bei dem nackten Protoplasmakörper anf einfachste Weise (nämlich durch Herabminderung der Spannung der Amöbenoberfläche durch Einwirkung des Chemotaktikums auf dieselbe) vor sich gehen wird, so müssen doch stets die Bewegungsorgane der chemotaktisch angezogenen Zellen in zweckentsprechender Weise in Gang gesetzt werden. Amöben oder Lenkocyten, die einem Chemotaktikum folgen, müssen mit Hilfe ihrer Pseudopodien nach dem Chemotaktikum hinkriechen, die Spermatozoen oder die Flagellaten müssen unter denselben Verhältnissen ihre Geißel gebrauchen, nie werden sie wie passive Lasten, wie Eisenfeilspänchen von einem Magneten angezogen. Die Erscheinungen der Chemotaxis sind stets aktive, wenn auch von außen einseitig beeinflusste Bewegungen der chemotaktisch wandernden Zellen selbst, niemals passive Bewegungen.

Zu bestimmt gerichteten »aktiven "Bewegungen sind stets besondere Bewegungsmechanismen nothwendig; ohne letztere sind jene undenkbar.

Ganz abgesehen davon, dass wir nicht das geringste Recht besitzen, die Fähigkeiten und Thätigkeiten, die wir als die chemotaktischen Erscheinungen an ganzen Zellen wahrgenommen haben, auch nun, wie das schon öfter geschehen ist, auf »einzelne Zell- 
bestandtheile «, in unserem speciellen Falle auf die rothgefärbten Körperchen also, zu übertragen, so kann auch ein chemotaktisches Hinwandern der Körnchen nach dem Gesagten desshalb für unwahrscheinlich gelten, weil bei den FischeL'schen Körperchen weder Pseudopodien, noch Geißeln, noch sonstige Bewegungsorgane gesehen worden sind, und weil die Anwesenheit von solchen etwa übersehenen oder unsichtbaren Bewegungsorganen auch von vorn herein wegen der einfachen homogenen Struktur der Körperchen im höchsten Grade unwahrscheinlich ist.

Die Zusammenscharung der Körnchen kann also auch unserem hentigen Wissen nach nicht anf die Ausscheidung eines auf die Körnchen wirksamen Chemotropikums von Seiten des Kerns und seiner Sphären zurückgeführtwerden.

Da wir weitere aktive Bewegungsarten kleiner Körperchen im Organismus nicht kennen, so kommen wir zu dem Schlusse, dass sich die Zusammenscharung der Körnchen heut zu Tage iiberhaupt nicht mit aktiver Bewegung der Körnchen erklären lässt.

b. Beruht die Zusammenscharung der Körnchen auf passiver Verlagerung?

Lässt sich aber eine aktive Bewegungsthätigkeit der Körnchen nach dem hentigen Stande unseres Wissens als höchst unwahrscheinlich - mit unseren heutigen Erklärungsmitteln als direkt unmöglich - darthun, so ist es selbstredend auch unwahrscheinlich, dass die Verschiebung der Körnchen gleichzeitig unter aktivem Hinwandern und passivem Hingetragenwerden stattfindet, und es bleibt nun zu prïfen, ob denn ein passiver Transport der Körnchen allein nach unserem heutigen Wissen eine ungezwungene Erklärung finden kann.

Ich halte die nachstehende, auf Grund der von mir entwickelten Zelltheilungsmechanik gegebene Erklärung für so ungezwungen und naheliegend, dass ich in den Befunden Fischel's abermals eine neue, von der lebenden Zelle selbst gelieferte Bestätigung meiner Theorie erblicke.

Die Körnchen liegen vor Beginn der Cytokinese allwärts im Protoplasma vertheilt. Nach Ausschluss der Aktivität soll ihre Zusammenhäufung eine passive, d. h. durch die Bewegung anderer Zelltheile passiv bewirkte sein. Wir werden also zunächst zu prïfen haben, welche Verschiebungen während der Cytokinese im Protoplasma vor sich gehen, um daraus schließen zu können, ob ein Theil des Protoplasmas etwa eine den Fisciel'schen Körnchen konforme 
Verschiebung erleidet, und ob dieser Theil dann als der aktive Träger der Körnchenbewegung angesehen werden darf.

r. Substanzverschiebungen im Protoplasma.

In Anschluss an Bütschli auf dem Standpunkt der Wabentheorie stehend, behaupte ich, dass zn Beginn der Cytokinese, also zu der Zeit, wo sich die rothgefärbten Körnchen um Sphären und Kern ansammeln, zunächst die Sphären, dann aber auch der Kern dem Waljenwerk des umgebenden Protoplasmas unter eigener Aufquellung Flissigkeit entziehen (warum und auf welche Weise of. Rhumbler, 96). Diese Flüssigkeitsentziehung wird zur Folge haben, dass das den Sphären und dem Kern anliegende Wabenwerk des Protoplasmas einmal eine Verdichtung seiner Wandsubstanz (des Hyaloplasmas) und dann eine Verkleinerung der Wabeninhaltsmassen (des Enchylemas) erfährt.

Die Verzähigung, d. h. die Verdichtung des Hyaloplasmas (der Wandsubstanz) um Sphären und Kern hat dann aber weiter zur Folge, dass die Enchylematröpfchen (d. i. die Wabeninhaltsmassen) ebenso wie vielfach die Dottereinlagerungen von Sphären und Kern hinweg nach der Zellperipherie gedrängt werden. Aus folgenden Gründen: die Verdichtung muss natiirlich von Sphären und Kern aus nach den peripheren Theilen der Zelle hin ständig abnehmen. Der nach den Sphären und dem Kern gewendete Theil einer jeden Enchylemavacuole wird daher unter einem größeren, von der Kohäsion des dichteren Hyaloplasmas ausgeubten Druck stehen, als der nach der Zellperipherie gewendete Antheil der Enchylemavacuole, der ja von einem weniger dichten, weil von dem Verdichtungsherd der Sphären und des Kerns weiter abliegenden, Hyaloplasma umfasst wird. Kurz gesagt: bei jeder Wabe ist der (durch den Verdichtungsgrad bestimmte) Kohäsionsdruck der Hyaloplasmawand auf das Enchylematröpfchen am inneren centralen Theil größer als äm äußeren peripheren Wabentheil, weil ersterer dem Verdichtungscentrum näher, letzterer von demselben weiter entfernt liegt. Die Enchylemaalveolen werden sich daher dem Verdichtungsgefülle des Hyaloplasmas entsprechend peripheriewärts bewegen und dadurch die Gesammtverdichtung des Protoplasmas um Kern und Sphären herum wesentlich erhöhen. Nicht bloß die Wandsubstanz der an Sphären und Kern anschließenden Vacuolen wird also verdichtet werden, sondern die Vacuolen selbst werden peripheriewärts verschoben. Das gesammte Plasma erfährt 
auf diese also doppelte Weise sein empirisch lange festgestelltes dichteres Gefiige um die Kernfigur herum.

Wie auf Grund der hier gegebenen Verdichtungsmeehanik die Strahlungen entstehen, habe ich schon früher eingehend behandelt. Nur müchte ich hier noch einmal besonders in extenso darauf hinweisen, dass das durch die Verdichtung des Kerns und der Sphären bewirkte centro-peripheriewärts gerichtete Kohäsionggefälle des Hyaloplasmas nur äußerst gering zu sein braucht, um das gegen die Peri-

Fig. 6.

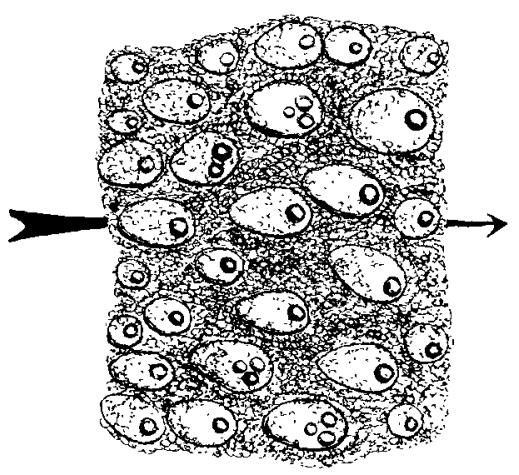

Weiße Dotterkörperchen des Huhnereidotters werden unter dem Leckglaschen durch Aufdrücken einer Nadel aut dasselbe einem einsoitigen suhwachen Drucke ausgesetzt, der iu der Kichtung des Pfeiles uì gesammte Eimasse fortbewegt und wach dem Deckglasrande hin (cf. Pfeilspitze) an Stirke abnimmt. I)ie Dotterkörperchen haben ovoide form angenommen, weil ihr der Pfeilspitze zugekehrter 'l'heil unter geringerem Druck als ihr dem Pfeilende zugewendeter Theil steht. Die Fettröpfehen der Wotterkórpercheu sind ohne Ausnahme in den vorderen, unter geder Dotterkërperchen eingetreten. Vergr. $300 / 1$. ringerem Druck stehenden, a ufgebauschten Theil

pherie gerichtete Abwandern der Enchylemaalveolen zu bewirken. Ein Experiment, das ich schon einmal bei anderer Gelegenheit ausgeführt habe (98b, pag. 135 ), wird das beweisen.

Bringt man eine Portion des Hiihnereigelbes rasch unter ein Deckglas, und beobachtet man diejenigen weißen Dotterkörperchen, die bloß ein oder doch nur wenige Fettröpfchen enthalten, während man mit einer Präparirnadel einen ganz leisen Druck auf das Deckgläschen ausiibt, so nimmt man folgende Erscheinungen wabr. Das ganze Eigelb fließt natürlich dem Druck entsprechend mehr oder weniger rasch von der Druckstelle weg dem Deckglasrande zu. Die Dottertröpfehen selbst verlassen ihre kugelige Gestalt und werden eiförmig; ihr breiteres Ende dem Deckglasrande zugekehrt, bewegen sie sich mit dem gesammten Eigelb nach dem Deckglasrande zu. Es ist hierbei schon auffallend, dass die doch ganz geringen Druckdifferenzen, in welchen sich der druckwärts und der deckglasrandwärts gelagerte Pol der Dotterküüelchen befinden, die kugelige Form der Dotterkügelchen in die geschilderte ovoide umzuwandeln vermögen. Die Erweiterung des deckglasrandwärts gewendeten Theiles des Dotterkörperehens ist ganz selbstverstïndlich durch den geringeren Druck verursacht, den die Nähe des Deckglasrandes, nach dem hin die Eimasse ansfließen kann, mit sich bringt. 
Fuir uns wichtiger ist aber das Verhalten der den Dotterkuigelchen eingelagerten Fetttröpfehen, sie wandern alle dem breiteren Theil des Ovoids zu, der nach unserer Auseinandersetzung unter geringerem Druck steht; kein einziges tritt in den zugespitzten, stärker gedriickten Theil des Oroids, auch keins bleibt in der mehr centralen Lage, die es in dem ungedriickten Dotterkörjorehen inne hatte, liegen. Die Fetttröpfchen verhalten sich hier also ganz wie sich nach unserer Erörterming die Enchylematröpfehen in den durch die Wirkung der sphären und des Kerns central verdicliteten und zusammengezogenen Wahenwerk der Zelle verhalten. Obgleich bei der geringen Größe der Dottertröpfehen und bei der Schwachheit des auf das Deckgläschen ausgeübten Druckes die Druckdifferenzen im druckwärtigen und randwärtigen Theil des Dottertröpfchens nur äuBerst minimale, kaum messbare sein können, verlageru sich die Fettröpfehen in den minimal schwächer gedriickten Theil der Dotterkigelchen. Ergo brauchen auch die Druckdifferenzen in dem Alveolenwerk des Hyaloplasmas keine großen zu sein, um die peripheriewärtige Abwanderung der Enchylematröpfchen aus der Protoplasmaverdichtung zu erklïren. Ich sage, sie »brauchen "nicht; sie können natiirlich von einem gewissen, durch die Reibung gesetzten Minimum ab beliebig groß sein, je grö̈Ber sie sind, desto rascher wird sich unter sonst gleichen Bedingungen die Protoplasmaverdichtung um sphären und Kern vollziehen und von dem ibrigen Protoplasma absetzen.

Die Größe der 1)ruckdifferenzen an dem druckwärtigen und distalen Theil der Einlagerung, der Enchylematröpfehen oder der Fetttröpfchen wird nicht nur von dem Druckgefälle selbst, sondern auch von der Größe der Einlagerung abhängen. Je grö̉ßer die Einlagerung ist, desto weiter wird sie natürlich in die Gegend des höheren Drucks auf der einen und in die des niederen Drucks auf der entgegengesetzten Seite hineinragen. Im gleichen Druckgefülle werden sich daher größere Einlagerungen schneller und weiter von dem Verdichtungscentrum fortbewegen, als kleinere Einlagerungen derselben Art*. Hier tritt noch hinzu, dass für größere Einlagerungen, wie wir bald sehen werden, die Reibung »relative geringer ist als für kleinere Einlagerungen, so dass anch desshalb größere Einlagerungen leichter verschoben werden als kleinere. Das wird aufs deutlichste dadurch für die Zelle belegt, dass oftmals kleinere Dotterkörperchen bei der Eitheilung 
in der Nähe der Sphären verharren, während alle gröBeren peripheriewärts verlagert werden.

Fs braucht wohl nicht näher ausgeführt zu werden, dass das, was für die Enchylematröpfehen im Hyaloplasma und für die Fetttröpfehen in den weißen Dotterkörperchen des Hühnereies gilt, auch für flüssige und feste Einlagerungen anderer Art im Hyaloplasmawandgeriist des Wabenwerks Geltung haben muss; doch mag die bereits früher von mir gegebene Fignr und ilıre Erklärung nochmals hieran erinnern (Fig. 7). Die Einlagerung ist hier als fest angenommen, sie soll etwa eine Dotterscholle repräsentiren. Wäre sie flüssig, so müsste ihr in der Bewegung:

Fig. 7.

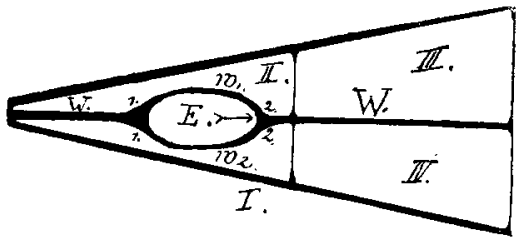

Suhema, soll die Abwanderung fremder kinlagerungen ( $F$ ) aus der Sphärennāhe erläutern. Die gemeinsame Wand $(W)$ der beiden Waben $I$ und $I I$ ist durch $E$ in $z$ wei Wände $(u$ und $w *$ aus einander gedrängt worden, bei 1 werden diese Wande. Wuil llier wegen der s̈phärennithe dis Hyaloplasma zahftüssiger ist als bei 2 , stärker auf einander gepresst als bei 2 . Die Einlagerung $F$ muss daher in der Richtung des Pfeiles nacl den Waben $I I I$ und $I 7^{\circ}$ hin wandern, bei dieser Wanderung wird sie die Lase geringsten Widerstandes aunebmen, d. h. ihre Langsachse wird sich in die Bowegungsrichtung einstelleu. voranschreitendes, unter geringerem Druck stehendes Ende ebenso verbreitert sein, wie wir das bei dem Dottertröpfchen gesehen haben, oder falls ihre Oberflächenspannung dem Druck gegenüber sehr groß wäre, so müsste sie mehr oder weniger kugelige Gestalt besitzen.

Es kommt ferner aber bei der Fortbewegung der Einlagerung rom Verdichtungscentrum nicht bloß auf die seither allein beriicksichtigten Druckdifferenzen an, unter welchen sich der der Verdichtung zugekehrte und der ihr abgewendete Theil der fluissigen oder festen Einlagerung befindet, sondern in hohem Grade natirlich auch auf die Reibung, welche die Einlagerung bei ihrer Fortbewegung am Hyaloplasma erfährt. Diese Reibung muss geringer sein, als die Kraft, mit der die Druckdifferenzen die Einlagerungen von der Stelle höheren zu derjenigen niederen Druckes zu verlagern suchen, das ist ganz klar.

Der Grad der Reibung hängt aber außer von der Schwerkraft, deren Wirkung wegen der geringen Differenz zwischen dem specifischen Gewicht der Einlagerungen und des Protoplasmas (cf. RHumbLER, 96, pag. o 47) mur in seltenen Fällen in Betracht zn ziehen sein wird, in iberwiegend hervorragendem Grade von der Größe, von der Gestalt und von den Kohäsions- und Adhäsionsverhältnissen zwischen Einlagerung und Hyaloplasma ab. 
Bei gleicher Gestalt und anch sonst gleichen Verhältnissen werden gröbere Einlagerungen immer leichter abwandern als kleinere, weil sie eine im Vergleich zu ihrem Volumen srelative, natürlich nicht *absolut " kleinere Oberfläche besitzen, also relativ geringere Reibung erfahren werden, als kleinere Einlagerungen ${ }^{1}$ ).

Leichtfliissige Substanzen, wie das Enchylema ${ }^{2}$ ), werden wegen der leichten Verschiebbarkeit ihrer Randmolekeln, die eine geringe Reibung bedingt, sehr leicht von der Verdichtung der Sphären zurückweichen ${ }^{3}$ ). Bei Einlagerungen von stärkerer Kohäsion, d. h. bei sehr zähfliissigen oder gar festen Einlagerungen, wird es aber sehr daron abhängen, wie groß ihre Adhäsion zum Hyaloplasma ist. Ist ihre Adhäsion ${ }^{4}$ ) zum Hyaloplasma größer als die Kohäsion des Hyaloplasmas, so werden sie sich nicht aus dem Hyaloplasma höheren Druckes fortdrticken lassen, weil sich mit dem höheren Druck, mit der dichteren Lagerung der Molekiile, auch die Adhäsion steigern wird, so dass sie sich an den stärker drickenden Hyaloplasmatheil, der sich ja selbst nicht fortbewegt, auch fester anklammern werden als an den weniger driickenden Theil des Hyaloplasmas $\left.{ }^{5}\right)$.

Auch hier deckt sich die Mechanik des Zellorganismus wieder einmal, wie so oft, mit der Zweckmäßigkeit. Diejenigen Substanzen oder Substanzkomplexe nämlich, die mit dem Hyaloplasma auch während der Verdichtung desselben zu seiner Instandhaltung, zu seiner

1) Bei kageliger Gestalt der Einlagerungen nimmt mit dem Größerwerden der Kugeln nach bekannten Gesetzen die Oberfläch nur im Quadrat des Radius zu, während das Volumen sich in der dritten Potenz steigert. Eine Kugel $b$ z. B., die $27 \mathrm{mal}$ so viel Inhalt hat als eine andere Kugel $a$, hat nicht eine auch $27 \mathrm{mal}$, sondern bloß $9 \mathrm{mal}$ so große Oberfläche als $a$. Auch bei anderen Formen werden bei gleichbleibender Gestalt kleinere Einlagerungen eine relativ größere Oberflïche besitzen als größere Einlagerungen. Die größeren werden also immer leichter fortgedriickt als kleinere.

2) Die Zähfliussigkeit des Protoplasmas wird durch die starke Zïhfliussigkeit des Hyaloplasmas bedingt; das Enchylema stellt dagegen eine dünnflüssige, wohl fast wasserfluissige Substanz dar.

3) So wird sich z. B. selbst aus einer feuchten Thonmasse, die selbst sehr zäh ist, Wasser verhältnismäßig leicht noch durch partiellen Druck von der Druckstelle wegpressen lassen.

4) Dabei muss natïrlich ihre eigene Kohäsion größer sein als ihre Adhäsion zum Hyaloplasma, sonst würden sie sich im Hyaloplasma lüsen, könnten also gar nicht als Körnchon im Plasma erscheinen.

5) Mit dieser Auffassung steht die Aunahme der Physik in gutem Einklang, dass die Reibung in strömenden Flüssigkeiten unabhängig ist von dem Drucke, der im Inneren der strömenden Flïssigkeit vorhanden ist. Vgl. WüLLNER. Experimentalphysik. 3. Aufl. 1874. pag. 324. 
Ernährung oder zu anderer chemischer Wechselbeziehung nothwendigsind, werden aus dem Druckeentrum nicht entweichen. Weil, wie ich friiher schon (Rrumblek, 98, pag. 252) klargelegt zu haben glaube, Austausch- und Umtauschgeschäfte zwischen derartigen Einlagerungen und dem Hyaloplasma, also Arbeitsleistungen, die nothwendig mit der Erhaltung und Ernïhrung verknüpft sein muissen, eine unbedingt große Adhäsion bedingen. Derartige Umtauschgeschäfte sind nur dann denkbar, wenn die umgetausehten stotfe zu derjenigen Substanz, in die sie iibertreten, eine größere Adhäsion als eigene Kohäsion besitzen.

So werdeu die chemisehen Wechselbeziehungen, die man zwischen Keru und Hyaloplasma wird amnehmen dürten, schon für sich allein verhindern, dass der Kern, welcher unter anderen Bedingungen als eine grobe Einlagerung sehr bald und energisch aus der Verdichtung der Muttersphäre weggetrieben werden müsste, auch zu einer. Zeit, wo er selbst noch nicht durch Linchylemaaufsaugung zu einem Verdichtungscentrum des Wabenwerks wird (cf. RnUmbler, 96, pag. 586), oder zu der Zeit, wo er von den beiden Sphären noch nicht in die Mitte genommen worden ist, aus der Niihe der Muttersphäre fortgetrieben wird.

Was aber für die große Einlagerung des Kerns als guiltig erscheinen muss, wird in weit höherem Grade noch für kleinere bis kleinste Einlagerungen gelten. Die kleinsten Einlagerungen sind an sich schon durch ihre relativ größere Reibung und die geringere Strecke, die sie im Druckgefälle mit ihrem Volumen einnebmen, vor einer Verlagerung so viel mehr als größere Einlagerungen geschützt, dass schon ganz geriuge Anstauschgeschäfte mit dem umgebenden Hyaloplasma ausreichen werden, sie in ihrer ursprïngliehen Lagerung im Dichtigkeitsgefälle des Hyaloplasmas festzuhalten. Dahei ist es einerlei, ob derartige kleinste Körperchen selbst Stoffe an das Protoplasma abgeben, oder ob sie solche von dem Protoplasma als etwa tiherfluissig gewordene. Stoffe erhalten. Der Umtausch bedingt die große Adhäsion zwischen Hyaloplasma und Körperchen, in welcher Richtung dieser Umtausch verlïuft, ist einerlei. Es können sich also Körperchen des regressiven oder progressiven Stoffwechsels in gleicher Weise im verdichteten Hyaloplasma halten, und um so besser, je kleiner sie sind.

Es soll mit dem Vorstehenden nicht gesagt sein, dass große Adhäsion zum.Hyaloplasma nur etwa im Stoffiwechsel mitarbeitenden Körperchè zukommen könnte. Ganz gleichgültige indifferente 
Körperchen könnten a priori auch zufällig einmal eine größere Adhäsion zum Hyaloplasma haben als die Kohäsion des Hyaloplasmas und könnten sich dadurch der Verdrängung aus dem Verdichtungscentrum widersetzen; chemische Wechselwirkung ist an Substanzen ron großer Adhäsion gekniipft, aber große Adhäsion nicht nur an chemische Wechselwirkung. Auch wenn die Adhäsion der Einlagerungen gleich der Kohïion des Hyaloplasmas ist oder ibr annähernd gleicht, werden Einlagerungen ron der Verdichtung nicht verdrängt werden, sie hängen dann an dem Hyaloplasma mit derselben Kraft fest, mit der die Hyaloplasmatheilchen selbst unter einander zusammenhängen, und werden sich desshalb, so lange sie allseits von Hyaloplasma umgeben sind, auch ganz wie Hyaloplasmatheilchen verhalten, $d . \mathbf{b}$. sie werden nicht verdrängt werden.

\section{c. Beantwortung der ersten Frage nach den Ursachen} der Körnchenzusammenscharung.

Unsere Antwort lautet: Die Körnchen wandern nicht nach Sphären und Kern'hin, sondern sie werden mit dem Hyaloplasma, zu dem sie offenbar eine genügend starke Adbäsion besitzen, nach dem Verdichtungsherde der Sphären und des Kerns hin zusammengezogen. Das Hyaloplasma wird um Sphären und Kern verdichtet, das Enchylema wird mehr oder weniger weit peripheriewärts verdrängt, und während desshalb Sphären und Kern ron einem dichteren Protoplasma umgeben werden und die peripherischen Zelltheile erfahrungsgemäß weniger dicht erscheinen, muissen in dem verdichteten Protoplasma die vorher in dem Zellleib allwärts zerstreuten Körnchen auch dichter gehäuft und in dem verdünnten Protoplasma auch nur spärlich zerstrent erscheinen; denn die Körnchen haben sich durch ihre Adhäsion zum Hyaloplasma vor einer Verstoßung aus dem Verdichtungscentrum bewahrt, und ihre Lagerung ist desshalb im Verdichtungscentrum dichter, in der verdünnten Substanz der peripherischen Zelltheile dagegen sehr viel spärlicher geworden. Dass dieser Erklärung entsprechend die Körnchen im peripheren Zelltheile nicht ganz fehlen, hat Fiscuers selbst hervorgehoben $\%$.

1) Man wird vielleicht durch Zählung der Körnchen (vorausgesetzt, dass sie im Ruhezustand der Zelle gleichmäßig vertheilt sind) auf einer gewissen Raumeinheit im Ruhezustand der Zelle, und dann durch Fesststellung der Körnchenzahl auf derselben Raumeinheit in den verschiedenen Verdichtungszonen ein zahlenmäßiges Maß für die Verdichtung berechnen können. Aus den 
a. Übereinstimmung der gegebenen Erklärung mit Fischel's Bismarckbraun-Färbungen und eventuelle Übereinstimmung mit Bütschli's Beobachtungen an Gelatinestrahlungen.

Die gegebene Erklärung lässt olne Weiteres anch die Resultate der von Fischel ausgeführten Bismarckbraun-Färbungen verständlich erscheinen.

Der ganze Zellleib scheint dabei während der kuhe diffus hellgelb gefärbt; besondere Körnehen treten nicht hervor. „Während der Theilung dagegen ist oft der centrale um den Kern gelegene Abschnitt stïrker gefärbt als der peripherische. Offenbar färbit das Bismarekbraun das Hyaloplasma selbst, und die stärkere Färbung um die Kernfigur herum während der Theilung ist bloB der direkte Ausdruck für die hier stattfindende Protoplasmaverdichtung. Die "iiber die ganze Zelle ausgebreitete Färbung" des Ruhestadiums entspricht der gleichmäßig ausgebreiteten Vertheilung des Hyaloplasmas anf diesem Stadium.

Hier mag schließlich noch eine Beobachtung Bürschtrs an künstlichen Strahlungen Erwähnung finden, welche möglicherweise auf ähnlichen mechanischen Bedingungen beruht (Bëtschl, 98, pag. 157).

Bérschul hat bekanntlich in dem wabigen Geriist erstarrender Gelatine Strahlungen um durch Abküblung in Kontraktion versetzte Luftblasen erzielt, die den Protoplasmastrahlungen um die Sphärenverdichtung in Theilung befindlicher Zellen bis in weitgehende Details ähnlich sehen. Uber die mechanischen Vergleichspunkte der künstlichen und natürlichen Strahlungen bitte ich außer BütschLI (93) anch meine früheren mechanischen Erörterungen (96) nachzusehen.

Bei derartigen Gelatinestrahlungen, die stark mit aufgeschwemmtem Berliner Blau versetzt waren, erschien der Verdichtungshof um die Luftblase dunkler blau als die Umgebung. = Mit den stärksten Vergrößerungen ließen sich jedoch in den Höfen meist nur sehr wenig Partikelchen des Berliner Blau unterscheiden, die Färbung ersehien mehr diffus oder homQ-

Figuren FischeL's geht jetzt schon hervor, was sich von vorn herein erwarten lisst, dass die Verdichtung un Sphären und Kern herum sehr rasch nach der Peripherie hin abfällt. Die Imbibitionskraft von Sphären und Kern, welche die lokale Verdichtang des Wabenwerks hervorruft, wird mit dem Quadrat der Entfernung abnehmen; die Verdichtung selbst wird in der dritten Potenz sinken, denn die Ausbreitung der Imbibitionskraft wird in den Dimensionen von immer größer werdenden Kugeloberfächen vor sich gehen, das Wabenwerk aber, auf welches die Kraft wirkt, ist körperlich, es wird sich in den Dimensionen der Kngelvolumina der Einwirkung der Imbibitionskraft darbieten (cf. Bútschl, 98 , pag. 158 ). 
gen. Dass dies zwar wirklich der Fall ist, möchte ich bezweifeh; ich halte es für wahrscheinlicher, dass in dem aufgeschwemmten Berliner Blau eine große Nenge feinster Partikelchen vorhanden sind, die wegen ihrer Kleinheit nicht mehr wahrgenommen werden, und suche daher die intensivere und anscheinend diffuse Färbung des Ilofes darin, dass in dem dichteren Hof diese Partikelchen auch in relativ größerer Menge vorhanden sind und dessen intensiveres Blau bedingen " Diese Auffassung entspricht ganz dem, was vorher entwickelt worden ist 2 ). Die kleinsten Körnchen werden sich in der Verdichtung haben halten können, während größere daraus verdrängt worden sind; die nicht verdichtete Gelatine zeigt weniger Berliner Blan und erscheint heller als die verdichtete; die starke Färbung des Verdichtungshofesentspricht wahrscheinlich der Körnchenzusammenhäung im Echinodermenei.

\section{Warum rücken die Körnchen bei der Bildung der Zellscheidewand aus der Spindeläquatorebene ab? Bütschli's Gelatinespindeln.}

Das Verschwinden der Körnehen aus der Äquatorialebene ist daranf zurickzufuhren, dass der Kern auf dem Stadium der Zelltrenuung, das ich als Cytodiärese bezeichnet habe, sein Imbibitionsstreben gesittigt hat und somit einmal nicht mehr verdichtend auf das umgebende Protoplasma einwirkt. Andererseits aber wird nunmehr dureh den polwärts gerichteten Zug der Sphären der Kern in die Länge gezogen und sein flüssiger Inhalt dadurch unter so hohen Druck versetzt, dass ein großer Theil des Kernsaftes aus dem Kern, der seine Membran anfgelöst hat, ausgepresst wird, und sich nun hier in der Äquatorebene der Zelle ausbreitet, wo, wie gleich noch näher aus einander gesetzt werden soll, geradezu eine Saugkraft auf ihn ausgetubt werden muss. Indem sich der Kernsaft in dem Hyaloplasmagerust der Äquatorgegend ausbreitet, nimmt dieses ein quantitativ weniger dichtes Gefüge an, und die vorher zusammengedrängten Körnchen werden jetzt auf einen größeren Raum

1) Von mir gesperrt.

2) Für absolut sicher kann sie jedoch, wie Bürschut ja schon dentlich ausgesprochen hat, nicht gelten. Es scheint mir auch leicht möglich, dass die Berlinerblaukörnchen unter dem höheren Druck des Verdichtungshofes zerdrückt worden sind, und sich desshalb stärker färbend diffus im Hofe verbreitet haben. 
vertheilt, d. h. ibre augenfällige Zusammenbäufung verschwindet.

Wenn man die ganz vortrefflichen. Photographien betrachtet, die Bütscrul ron kïnstlich zwischen zwei Luftblasen entstandenen

Fig. S.

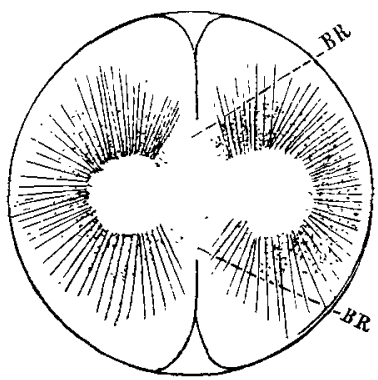

Fig. 9.

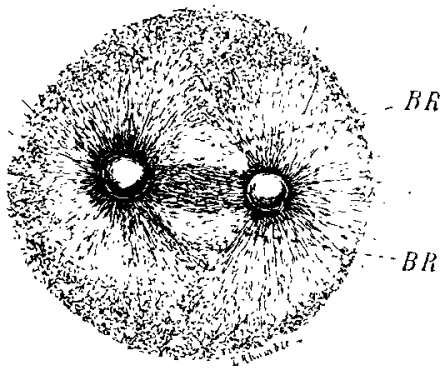

Fig. s. Mit Noutralroth gefärbtes lebendes Ei von Echinus microtuberculatus wăhrend der Entstehung der ersten Furche. Die Frschel'schen Körnchen sind aus der Ebene der entstehenden Zellseheidewand abgerúckt. Vergr. 300/1. Nach Frscine, 19.

Fig. 9. Line nach Bürschli's Angaben (Bütschlı, 49) hergestellte künstliche Spindel zwischen zwei Luftblasen in einer warmen, ziomlich stark koncentrirten wảsserigen Gelatinelösung während des Erkaltens entstanden; dann in $0,3 \%$ iger Chromsäure fixirt, in $20 \%$ igem Formol gehàrtet und mit Süurefachsin gefärbt. Beiderseits der Centralspindel die hellen Bctschlíschen Räume ( $B R$ ). Mran rergleich $\theta$ die Lagerung derselben mit den Stellen, wo in Fig. $\overline{8}$ die Fiscirctschen Körnchen rerschwunden erscheinen. Nach der Firbung mit Sãurefuchsin haben die dunkel gezeichnete Spindel und die Gelatineverdichtungen om die Luftblase herum einen grellrothen Ton, die Busciur schen Raume aber eine bläulich rothliche Nuance angenommen. Die Figu ist auf dieselbr Größe abgerundet worden wie Fig. \&, um den Vergleich zu erleichtern. Auch die Veryrößerung isí annăhernd die gleiche. Vergr, $325 / 1$. Zeichenapparat.

Gelatinespindeln hergestellt hat, so wird sofort auffallen, dass diese Spindeln im Äquator ron einem belleren, lichteren Raum umgeben

Fig. 10.

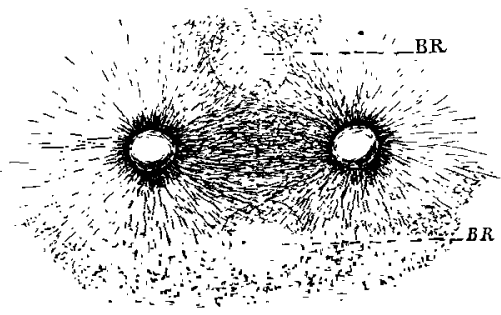

Fig. 10 wie Fig. 9. Jodoch habon sich hier die Bitsschli'schen Răume ( $B R$ ) mit einem scharfen Kontour gegen die Spindel hin abgesetzt. Diesar Kontonr wird in distaler Richtung weniger scharf. Vergr. 325/1. Zeichenapliarat. sind, auf dessen Existenz auch BürschLI besonders aufmerksam gemacht hat (BürschLi, 98, Taf. 1 Fig. 7 ; Taf. 2 Fig. 1 ; Taf. 21 Fig. 6 ; pag. 159), ohne jedoch eine Elklärung für denselben gefunden zu haben. Der helle Bërsschlysche Raum entspricht offenbar - das zeigt seine Lage /vgl. Fig. 8 und 9$)$ - dem Raum, aus welchem die Körnchenzusammenlagerung im Echinidenei während der Cytodiärese verschwindet.

In einigen meiner Gelatinespindelpräparaten (ef. Fig. 10) hat sich der Bërscmli'sche Raum direkt blasenartig beiderseits der 
Spindel entwickelt. Zuweilen läuft sogar ein hohler Kanal um die Spindel herum; es sammelt sich im Bürschli'schen Raume offenbar eine fliissigere Gelatine an, die sich unter Umständen mit mehr oder weniger scharfer Wandung von der iibrigen Gelatine absetzt.

Die Entstehnng des hellen Bütscint'sehell Raumes um die Gelatinespindel und die Abriickung der Fischel'schen
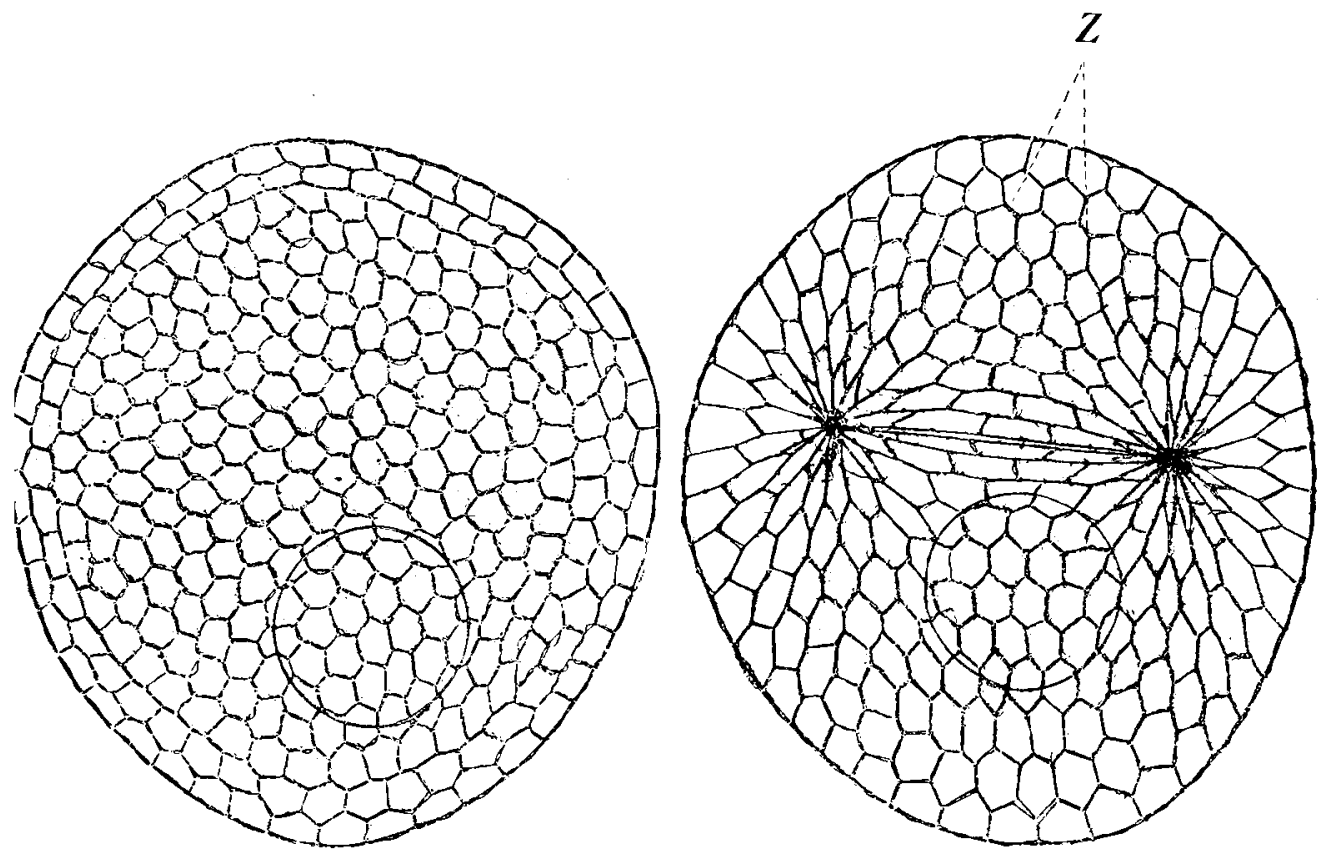

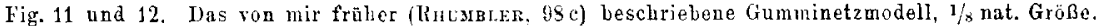
Fig. 11 in der Ruhelage mit aufgebundenen Kernreifen. Fig. 12. Durch Zug au zwei Stellen ist eine Spindelfigur mit Strablungen erceugt worden. In dem ron $Z$ umfassten Raum (cf. Bürscḱl'scher Raum in Fig. 0 und 10) sind die $\mathbf{l}$ asclen grōßer, in der Spindel kleiner geworden als im Ruhestadium des Modells. NB. Auch die Randmaschen sind größer als im Rabestıdium; es entspricht das dem Umstande, dass in den Randpartien der Zelle die Fiscreta'schen Körnchen dicht zusammengerückt erscheinen.

Körnchen ans der Theilungsebene haben ganz augenscheinlich iibereinstimmenden mechanischen Ursprung.

Betrachten wir das frïher (Rhumblen, 98c, pag. 543 ) von mir beschriebene, dureh lokaleZugwirkung an zwei Centren, zur Spindelbildung veranlasste Gumminetzmodell an den Stellen, die den Bürschur'schen Räumen bez. der Stelle der Körnchenabrückung im Ei entsprechen, also an der Stelle $Z Z$ und an der zu ilnr symmetrisch gelegenen Stelle der anderen Seite jenseits des dem Modell aufgebundenen Kernreifen, so finden wir hier die elastischen Netzmaschen größer 
als sie im Rubezustand (Fig. 11) sind; ihre Größenzunahme tritt, wie ich hoffe, deutlich hervor, wenn man sie mit dem Netzwerk vergleicht, welches in dem Kernreifen liegt, und welches dadurch, dass der Kernreifen dem Netzwerk in der Ruhelage aufgebunden worden ist, in dem Ruhezustand rerblieben ist. Deutlicher noch als in der einer Photographie entstammenden auf $1 / 8$ verkleinerten Abbildung tritt sie im Modell selbst hervor, wo die Größendifferenzen, natïrlich absolut nicht relativ genommen, 8 mal größer erscheinen. Vor Allem auffallend, und das interessirt uns hier am meisten, sind die Größendifferenzen der Maschenrüume an den namhaft gemachten Stellen (Z), den Spindelmaschen gegeniber. Die imnerste Lage der Spindelmaschen hat ihr Lumen fast ganz verloren, ihre Lüngswände erscheinen wie zwei die Centren verbindende dicht neben einander herlaufende Parallelen auf einander gepresst, auch die Wabenräume der nächsten Schicht sind noch erheblich, die der iubernächsten Schicht wenigstens noch merklich kleiner als die Räume des die Spindel umgebenden Wabenwerks und vor Allem der die Spindel umgebenden aquatorialen Theile, $d$. h. der Bürscinu'schen Räume.

Da das Modell ein getreues Abbild der Zug- und Druckverhältnisse giebt, welche zur Zeit der Cytodiairese nach meinen friberen Auseinandersetzungen $(96$, pag. 605-610) innerhalb des Wabengeriustes der Zelle herrschen, so ergiebt sich aus der besprochenen Sachlage ohne Weiteres, dass in der Kernspindel enthaltene Flïssigkeit aus derselben ausgepresst und rouden äquatorialen Wabenschichten aufgesaugt werden muss; denn die Waben der Kernspindel suchen sich, wie das Modell zeigt, unter dem beschriebenen Zuge zu rerkleineru, die äquatorialen Wabenlagen aber zu vergrößern.

Der Übertritt der Flïssigkeit aus der Spindel in die umliegenden Waben reranlasst in der oben angegebenen Weise die Entstehung des Bǘs'rhl'schen Raumes und die Körnchenrarificirung in der Theilungsebene der Zelle.

Wie aus meinen fruheren Arbeiten bekannt sein dürtte, halte ich den in der Zelläquatorebene angehäuften Kernsaft für diejenige Substanz, welche, mit der Zellmembran in Beruhrung gebracht, das »gesteigerte Wachsthum der Zellmembran* bewirkt ${ }^{1}$ ), ohme welches

1. Ich verstehe unter Kernsaft hier keine chemisch bestimmt modificirte Substanz. sondern nur die Flüssigkeit, welche sich in den Hohlräumen des Kerns befindet. Diese Flüssigkeit kann Substanzen ganz verschiedener Herkunft in sich gelöst enthalten, wie sie z. B. höchst wahrscheinlich die Nucleolen- 
aus rein mathematischen Griinden (RHumbiar, 97) die Zelltheilung einer membranhaltigen Zelle absolut undenkbar ist.

Diese Auffassung muss hier der oben hereits mitgetheilten Beobachtung Fischel's gegeniber noch gerechtfertigt werden, dass znweilen die Körnchenabriickung ron der Theilungsebene öfter auf der Seite zuerst erscheint, wo die Durchschnirungsfurche noch nicht sichtbar war, oder noch nicht so tief einschuitt als auf der anderen Seite.

a. Warum erscheint die Karnchenahrickung manchmal auf der mit der Einschnurung säumigen Seite der Zelle zuerst?

- Man wird ohne. Weiteres annebuen duirfen, dass bei der sicher ganz allmählichen. Zunahme der Zugwirkung der Sphären unter normalen Verhältnissen sehr bald eine ganz allmähliche, geringfügige Diffusion von Kernsaft in die äquatorialen Waben hinein stattfindet, so dass die Kellmembran diese Stoffe schon aufnehmen und wachsen kamn, ohne dass schon wegen der Geringfigrigkeit der diffundirten Menge ein merklicher Bütschlr'scher Raum auftritt. Ist aber die Diffusiou erst einmal nach der Membran hin eingeleitet, so wird die Membran die aus dem Kern ausgetretenen Stoffe wegnehmen und der Bürscurische Raum wird auch dann noch lingere Zeit, so laug der $\mathrm{Zng}$ der Sphären noch nicht zn grüBerer Höhe angewachsen ist, nicht eischeinen, weil die Membran noch die spärlich diffundirten Stoffe zu ihrem eigenen Wachsthum, das sich in der Einsenkung der Furche Ausdruck verschaffit, rerwendet. Frst wenn der Zug: der Sphären (in Folge der Ausraubung der Waben des Polargebietes durch die Sphären ef. Rhumberr, 96) sein Maximum erreicht, wird die Diffusion so stark, dass die Membran die aus dem Kern ausgepresste Flüssigkeit nicht mehr so schnell verbrauchen kaun als sie aus dem Kern austritt und der Bürschl'sche Raum bez. die Kürnchenabrickung erscheint daun erst, also zu einer Zeit, wo die Einfaltnug der Membram schon begonnen hat.

Denken wir uns nun diese erste allmähliche Diffusion des Kernsaftes auf irgend eine Weise, vielleicht durch eine zufällige besonders dichte Dotterzusammenlagernng, in dem ja nur wohl selten oder nie allwaits absolut gleich ausgebildeten Eiprotoplasma gestört, so

substanz gelöst enthält. Ob letztere oder ob andere Stoffe zur Membranbildung herangezogen werden, ist für die Mechanik der Zelltheilung ganz gleichgültig. Nur der Sulustanzaustritt aus dem Kern uad der Substanzverbrauch bei dem Membranwachsthum ist wesentlich. 
wird die Membran auf dieser Seite noch nicht wachsen und sich daher auch noch nicht einstïlpen können. Der Kernsaft staut sich jetzt nach der Seite hin, wo die Diffusion gestört ist, und bricht dann erst durch, wenn der Zug der Sphäre und der dadurch auf ihn. ausgetilute Druck so groß wird, dass or die Hindernisse, welche einer allmählichen Diffusion im Wege standen, iiberwindet. Diese mehr eruptive Diffusion, die mit dem Auftreten eines Bürssulit'schen Raumes verbunden sein muss, repriisentirt einen einfachen Fall, dei in der Mechanik wohlbekannten "periodischen Überwindung" von Widerständen. Während im ersten Falle einor ungehinderten allmählichen Diffusion die Membran sich schon vor der Erscheinung. des Bürschu'schen Raumes einfaltete, wird sich im zweiten Fall einer zufällig gehinderten Diffusion die Membrau vorläufig nicht einfalten, sondern der BürschL'sche Raum wird zuerst auftreten und dann erst die Einfaltung der Membran erfolgen.

Ich sehe in dieser Beobachtung eine weitere Bestätigung meiner friiheren Behauptung, dass die gemeinsame Arbeit mehrerer Zelltheilungsfaktoren die exakte Durchfiihrung der Zelltheilung sichert. Der Fisché'sche Befund passt so schön zu einem früher ron mir fingirten Beispiel, dass ich die betreffende Stelle hier anführe (RHumbier, 97, pag. 708 und 709).

"Man nehme z. B. an, dass aus irgend einem Grunde das gesteigerte Membranwachsthum [das zur Durchschniirung der Zelle nothwendig ist] beeinträchtigt worden sei. Die Sphären werden mit ihrer gewohnten Kraft an der Einschnürungsstelle der Membran ziehen, die Membran wird dem Zuge aber vorerst nicht folgen, weil das sonst übliche gesteigerte Membranwachsthum ausgeblieben ist. Trotzdem die Membran nicht folgen kann, wird die Sphäre von ibren Zugbestrebungen nicht abstehen, weil die verdichtende Wirkung des Centrosomas (RHumbler, 96, pag. 577), anf welcher die Zugkraft der Sphäre und ihrer Strahlen berult, nicht eher anfhört, bis das Centrosoma sein Imbibitionsstreben gesättigt hat. Diese Sättigung wird erst dann eintreten, weun der Attraktionsmantel der Sphäre eine bestimmte Dicke erreicht hat.

Wenn die Membran ohne Widerstand einem geringen Zuge folgte, wie das bei ungestörtem Membranwachsthum der Fall wäre, dann würde der Attraktionsmantel rascher und ohne besonderen Zugaufwand die Dicke erreicheu, die aus mechanischen Gründen das Ende seiner Wirksamkeit bedeutet, denn durch das Einräcken der Einschnürungsfalten verkürzen sich die Strahlen oder die nicht zu Strahlen ausgezogenen W.abenradien, und können dadnrch der Sphäre leichter das geforderte Hyaloplasma 
abgeben, als dann, wenn sie durch den Widerstand der Membran auf größerer Länge festgehalten werden und wenn dadurch ihre distalen Waben in größerer Entfernung von der Sphäre zu verharren gezwungen sind.

Jetzt aber muss er länger ziehen, da ihm das Hyaloplasma spärlicher zufließt; die Wabenradien werden. stärker angezogen, die Strahlen werden länger als sie sonst vielleieht waren. Unter dem erhöhten Zuge rundet sich entweder, wenn iiberhanpt möglich, die Zelle noch mehr ab, und liefert dadırch den nöthigen Membranüberschuss und das von dem Attraktionsmantel geforderte Hyaloplasina (durch Annäherung der Waben an die Sphäre), oder der erhähte Strahlenzug presst die Kernvacuole so stark zusammen, dass der seither zurïckgehaltene Kernsaft austreten und die Membranvergrößerung erwirken muss. Erst wenn mit der Membranvergrößerung die Membraneinschnïrung erfolgt, kann der Attraktionsmantel seine angestrebte Dicke erreichen und kommt mit ihr zur Ruhe. Die säumige Membran aber ist zum Nachholen ihres Versäumten gezwungen worden ${ }^{1}$ ). «

Da wo die Zellmembram sich einstïlpt, nimmt durch den Zugmechanismus der Sphären der Druck auf die Kernvacuole ab, da wo die Kernmembran resistent ist, nimmt $\mathrm{er} \mathrm{zu}$, so dass sich mit der Resistenz der Kernmembran auch die Wahrscheiulichkeit steigert, dass sie noch machträglich ihre zum Wachsthum nothwendigen Kernstoffe zugepresst erhält.

Man künnte denken, dass sich der ganze Kernsaft nach der Seite des niederen Druckes, also nach der Seite, wo die Finschnürfurche zuerst erscheint, entladen miisse; das ist aber desshalb nur bis zu einem gewissen Grade der Fall, weil der Kernsaft der mit der Einschniirung rückständigen Seite nicht durch die am stärksten gepressten Plasmamasse des centralen Spindeltheiles auf die andere weniger gepresste Seite der ungehinderten Diffusion hinïber kommen kann.

In dem Netzmodell (Fig. 12) nimmt, wie ich durch Versuche festgestellt habe und wie ohne Weiteres plausibel ist, das Zusammensinken der spindelmaschen und die Erweiterung der Masehen im Bürschut'schen Raum, also die Größendifferenz zwischen beiden um so mehr zu, je mehr man an den Zugcentren zieht. Das heißt aber auf die Zellver hältnisse iubertiagen: Ist der Austritt des Kernsaftes

1) Es ist das uibrigens nicht zum ersten Mal, dass sich eine von mir theoretisch angenommene Möglichkeit nachträglich verwirklicht hat (cf. RHUMBLER, $98 \mathrm{c}$, pag. 553 ). 
aus irgend einem Grunde behindert, so wird sich mit dem zunchmenden Spindeldruck gleichzeitig die Sangkraft der hinter dem Hemmnis liegenden äquatorialen Haschen steigern; diese Steigerung. des Druckes vor dem IIindernis und der Saugkraft hinter dem Hindernis wird einmal zur Überwindung des Hindernisses führen und dann nach Überwindung desselben ein sehr rasches Üherdiffundiren von dem gepressten spindeltheil in den saugenden $\ddot{A}_{\text {quatoriaitheil, }}$ d. h. die Entstehung eines Bür'schul'schen Raumes oder, auf die Zelle übertragen, eine Abriickung der Fiscnel'schen Kürnchen in

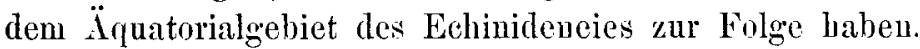

Also anch das Modell giebt uns kecht.

A uf der mit der Zelleinschnirung siumigen Zellseite wird die Körnchenvertheilung wegen gewaltsamerer Diffusion des Kernsaftes frïher erscheinen könneu, als auf der mit der Einschuïrung beginnenden Zellseite,. weil hier Anfangs eine allmählichere Aushreituag des Kernsaftes stattfindet, die erst beim Maximaltorg der Sphären so anwächst, dass dann auch hier die Körnchenvertheilung unter Kernsaftanfnahme der Plasmawaben erfolgt.

\section{Warum vertheilen sich die Fischel'schen Körnchen beim Übertritt in das Ruhestadium wieder allwärts in der Zelle?}

Die Riuckkehr der getheilten Tochterzellen in die Ruhestadien beruht nach meinen früheren Auscinandersetzungen (96, pag. 611) darauf: dass die Centrosomen schlieBlich nicht mehr im Stande sind, dem umgebenden Protoplasma Flissigkeit zu entziehen, dass so zu sagen unter den jeweils obwaltenden Verhältnissen eine "Sättigung" ilures Imbibitionsstrebens eingetreten ist.

Sobald aber dic Centrosomen ihre Imbibitionskraft verlieren, müssen sich auch die Zälhigkeitsdifferenzen zwischen der Verdichtung der Sphären und dem Hyaloplasma der umgebenden Waben ausgleichen $\left.{ }^{1}\right)$, und das in der Sphäre zusammengezogene Hyaloplasma

1) Man kann sich hierron durch Vergleich mit Kolloidsubstanzen, mit denen ja das Hyaloplasma so viel Ähnlichkeit haben muss, eine Vorstellung bilden. Wenn man eine zühflïssigere Lösung von Gelatine - die nach BürscriLI gleichfalls wabigen Bau besitzt - in eine dünner flüssige Lösung eintrügt. so wird auch die zähfliissigere durch Wasseraufnahme diinnfliissiger und die ganze Hischung erhält denselben Flïssigkeitsgrad. Es sind hier augenscheinlich osmotische Vorgänge in Wirksamkeit, die auch im Hyaloplasma einzutreten 
muss sich $\langle$ cf. 9j, pag. 546j in den Wabenwänden des Zellleibes vertheilen."

Die Antwort auf unsere dritte Frage lantet also: Bei der Vertheilung des Hyaloplasmas in den Wabenwänden werden die Fischel'schen Körnchen wieder ans den oben 'pag. 41-45! entwickelten Griuden mitgenommen und sie erscheinen dann wieder, wie die Fiscret'sche Beobachtung lehrt, allwärts in dem Zellleibplasma zerstreut.

\section{Einige Bemerkungen über die Aufnahme der Farbstoffe von aulsen.}

Obgleich mit der Beantwortung der drei Fragen der eigentliche Zweck dieser Abhaudlung: Fischel's Beobachtungen mit meiner Zelltheilungstheorie in Einklang zu bringen bez. dieselben mechanisch zu erklären, m. E. als erreicht anzusehen ist, kann ich es doch nicht untewassen, auch die Beobachtung. Fisches is, dass die dem Meerwasse zugesetzten Farbstofflösungen unter Entfürbung des Mediums offenbar ganz von den Echinodermeneiern aufgenommen und in den FischeL'sehen Kürnchen aufgespeichert werden, hier zu Gunsten einer von mir kürzlich (99, pag. 221) näher ansgefuihrten Behauptung anzufïhren.

Ich habe der Ausgestaltung der Zellmembran einen tiefgreifenden Einfluss bei der ansteigenden Komplikation der Embryonalzellen während der Ontogenie zugeschrieben. Die Begriindung bitte ich (Rhumbler, 99, pag. 227-229) nachsehen zu wollen. Die Zelloberflïche besitzt auf Grund der (ron mir namentlich in RHUnbler, 98, entwickelten) Importgesetze die physikalische Fähigkeit, zu entscheiden iber das, was in die Zelle anfgenommen und was von ihr ausgeschlossen wird. Zur Entscheidung dariiber, ob diese Fähigkeit von der Zelle benutzt wird, ist aber natiirlich der Nachweis nöthig, dass das Ei wirklich während seiner Entwickelung von außen Stoffe in sich aufnimmt, und nicht etwa bloß mit den Umsetzungsprodukten der Dotterpartikelchen arbeitet. Fuir den Sauerstoff der Athmung. ist eine solche Aufnahme von außen wohl ohne Weiteres anzunehmen; außerdem haben Henss's bekannte Untersuchungen die Aufnahme von außen für eine ganze Reihe von Stoffen für die Seeigeleier nachgewiesen.

scheinen. Ist schließlich im ganzen Zellleib das Hyaloplasma wieder anf denselben Fliissigkeitsgrad gebraclit, so muss es sich nach 96, pag. 546 wieder gleichmäßig in den Wabenwänden vertheilen. 
Was mir aber die Frschec'schen Versuche auch in dieser Beziehung besonders interessant erscheinen lässt, ist der Umstand, dass hier ein ganz unnöthiger Stoff in reichlichem Maße aufgenommen und offenbar aus dem Organismus nicht wieder entfernt wird. Der Schluss liegt nahe, dass die Aufuahme dieses für die Entwickelung. ganz gleichgïltigen Stoffes eine rein mechanisch-physikalische ist, bei der irgend ein vitalistisches Sondervermügen - das ich meinerseits ja iibcrhaupt nicht anerkenne ${ }^{1}$ ) - nicht in Thätigkeit ist; die Aufnahme des Stoffes geschieht nach einem unumgänglichen Gesetz, das für alle Larven gilt, dem Organismus ist hierbei der Entscheid entrissen, ob die anfgespeicherte Farbe ilım Nutzen bringt oder nicht.

Und das gilt offenbar nicht nur fiur die FrscineL'schen Körnchen, die einen nicht lebenden Theil des Protoplasmas darzustellen scheinen, sondern auch fiir das lebende Protoplasma selbst, wie die Bismarckbraunfärbungen darthun. (Man vgl. hierzu anch RHusbles, 9\$b, pag. 236, wo eine willenlose und mit der Zeit verderbliche Karminaufnahme von Testaceen angeführt wird.)

\section{Zusammenfassung.}

Wenn in cinem wabig gebauten Flisssigkeitsgemiseh, im Protoplasma oder in irgend einem emulsionsartigen Gemenge aus irgend welchem Grunde eine lokale Verdichtung der Wabenwandsubstanz ${ }^{2}$ ) eintritt, so entsteht in dem Wabenwandwerk ein Druckgefaille, welches von dem Verdichtungscentrum aus nach allen Seiten hin abfällt. Dieses Druckgefälle wird dadurch veranlasst, dass bei der Verdichtung die Kohäsion der Wandsubstanz gesteigert wird, die Wandtheilchen hängen an der Verdichtungsstelle unter einander fester zusammen und werden desshalb auf zwischen sie eingedrängte Substanzen einen größeren Druck ausüben, als da, wo eine geringere oder gar keine Verdichtung der Wandsubstanz eingetreten ist. Die

1) Ich erkenne wohl skomplexe Komponentens im Sinne Roux's (95, pag. 27) an, gestehe aber der organischen Matelie keine eigene Physik zu. Wo ich Materie, d. h. Masse, sehe, da muss meiner Überzeugung nach auch Physik und Chemie herrschen. Dass die physikalisch-chemischen Massengruppirungen dann außer physikalischen und chemischen Wirkungen noch andere Dinge, die psychischen Qualitiiten und Intelligenz im Sinne Reinke's, hervorbringen können, die s unserenc Begriffen der Physik und Chemie nicht zugïngig sind, das bestreite ich keinen Augenblick.

2) So weit ich ljis jetzt sehen kann, wird die Wandsubstanz stets eine Kolloidsubstanz im Sinne der Physik sein müssen. 
zwischen den Wabenwänden eingelagerten fliissigen Wabeninhaltsmassen, die Euchylematrüpfehen des Protoplasmas oder die Emulsionstrüpfehen einer Emnlsion, miissen daher von dem Verdichtung'scentrum der Wabenwandsubstanz, rom I)ruckgefalle fortgetrieben, abwandern; denn jedes einzelne dieser Fliissigkeitströpfehen ist an dem der Verdichtung zugekelrten Pole, einem durch die Verdichtung: verursachten höheren Kolïisionsdruck der Wandsubstanz ansgesetzt als an seinen der Verdichtung alggekehrten Pole, und diese Druckdifferenzen miissen sich innerhall) der flussigen Einlagerungen in der Weise auszugleichen suchen, dass die Einlagerung ron dem stiirker gedritckten nach dom weniger stark gedriickten Pole einfließt. Jede lokale Verdichtung (Kohäsionssteigerung) innerhalb der Wandsubstanz muss daher unter Abstoßung der fliissigen Einlagerungen glcichzeitig eine lokale Zusanmenhäufung der Wandsubstanz im Verdichtungscentrum und, andererseits eine Rarificirung der Wandsubstanz in den von dem Verdichtungscentrum abgelegenen Theilen der Emulsion zur Folge laben; denn in diesen abgelegenen Theilen nitissen sich selbstredend die ron der Verdichtung zuriickgestolienen Flüssigkeitstrïpfehen ansammeln.

Bei den Bürscuba'schen Gelatinespindeln') liegen zwei Verdichtungscentren (in Kontraktion befindliehe Luftblasen! dicht zusammen. Beide ziehen Gelatine zusammen und stoBen Lösungsflïssigkeit ron sich zuriuck. Die Lüsungstliissiggkeit muss sich daher in der auf der Mitte der Verbindungsachse beider Luftblasen senkrecht stchenden Ebene am stärksten ansammeln, jedoch nicht in der Verbindungsachse (= Spindel) selbst, weil hier der pag. 50 aus eimander gesetate Spindelmechanismus gerade eine besondere Verdichtung bewirkt : die Waben der spindel werden dureh Verdichtung ron beiden Seiten her ganz besonders stark verdichtet), sondern rings um die Verbindungsachse herum. Diese besondere Ansammlung von

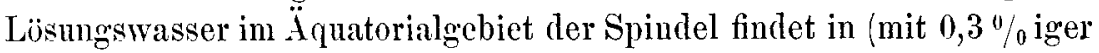
Chromsiure) konservirten Spindeln in dem Auftreten von hellen Räumen, welche die diinnfliissigere Konsistenz der Gelatine an dieser Stelle dokumentiren, ihren dentlichen Ausdruck (cf. Fig. 9 und 10). Diese von BÜTschu entdeckten Räume setzen sich manchmal sehr scharf von der übrigen Gelatine ab, so dass sie fast nur mit reinem Lösungswasser erfüllt erscheinen. Bei dicht zusammengelagerten größeren

1) Die Gelatine ist wabig gebant, in kleinsten Gelatinek ämmerchen ist ihr Lösungswasser eingeschlossen (cf. BüTsCHLI). 
Luftblasen habe ich einigemal den BürschLr'schen Raum sich in Röhrenform um den Äquatorialtheil der Spindel schlingen sehen. Man sieht wie die beiden Verdichtungscentren bestrebt sind, ihre Verdichtungsgebiete (cf. Zelltheilung;'; von einander zu trennen.

In dem Wabenwandsystem eingelagerte feste Körperchen werden sich je nach Größe und Beschaffenheit in einem Verdichtungs- bez. Kohäsionsdruckgefälle der Wahenwandmasse verschieden verhalten.

Besitzen sie eine große Adhäsion zu der Wabenwandsubstanz, so werden sie in dem Druckgefälle nicht abwandern, denn große Adhiision bedingt bei festem Aggregatzustand große Reibung während bei den vorbesprochenen fliissigen Einlagerungen wegen der leichten Verschiebbarkeit der Randmolekeln die Reibung eine gewisse verhältnismäßig geringe Größe nie iiberschreiten kann -. Sobald die Reibung größer ist als die abstoBende Kraft des Druckgefälles, kann natiirlich eine Abriickung der Einlagerungen ans dem Verdichtungscentrum nicht erfolgen. Namentlich kleine feste Kürperchen von großer Adhäsion zum Hyaloplasmawandgerist werden sich besonders leicht im Druckgefitle halten können; denn die Druckdifferenz zwischen ihrem der Verdichtung zugewendeten und ihrem derselben abgekehrten Pole wird natürlich um so geringer sein, je kleiner sie selbst sind. Die Größe der Druckkdifferenz ist aber nichts Andercs, als die Größe der abtreibenden Kraft. Kleinere Körperchen werden also an sich schon von dẹr Verdichtung weniger stark abgedrückt als größere Einlagerungen. Kleinere Körperchen haben aber anßerdem eine relativ (natürlich nicht absolut) größere Oberfläche als größere Einlagerungen; sie werden sich also anch desshalb bei genigender Adhäsion leichter in der Wandsubstanz halten können, als größere Einlagerungen.

Größere Einlagerungen im Wabenwandsystem werden bei geringerer Adhäsion zur Wabenwandsubstanz um so leichter abwandern, je größer sie sind und je geringer ihre Adhäsion zur Wandsubstanz ist.

So kommt es, dass einzelne Kategorien von Einlagerungen der sich verdichtenden kontrahirenden Wabenwandsubstanz folgen, andere dagegen ron ihr zurückgestoßen werden können.

1) Nur die Spindel selbst steht dieser Trennung entgegen. In der Zelle wird sie durch die Polstrahlen unter gelegentlicher Mitwirkung der Einschnijrungsfalten (Wachsthumstalten der Zellmembran) getrennt (RHumbLer, 96;. 
Werden Einlagerungen in Folge ihrer Kleinheit und genügender Adhäsion nicht von der Verdichtung weggestoßen, während Flüssigkeiten und andere größere Einlagerungen von geringer Adhäsion gleichzeitig aus der Verdichtung fortgestoßen werden, so miissen die nicht verstoßeuen Einlagerungen in dem Verdichtungsgebiet natiirlich dichter zusammengeschoben werden, als an den nicht verdichteten Stellen des Wabensystems, an denen sich die verstoßenen Einlagerungen ansammeln werden.

Die Resultate der Frschel'schen Vitalfärbungen an Seeigeleiern erklïren sich hiernach folgendermaßen:

Die während des Ruhestadiums in der Zelle allwärts gleichmäBig verbreitete Hyaloplasma-Wabenwandmasse wird während der Fliussigkeitsaufnahme des Kerns um den Kern herum verdichtet (Fig. 1). Dabei werden die Dottereinlagerungen und Enchylemavacuolen ron dem Druckgefälle nach den peripheren Zellpartien hiu verdrängt werden. Die FrsclisL'schen Körnchen aber bleiben in Folge ihrer Kleinheit nnd ihrer großen Adhäsion im Hyaloplasma liegen, und werden also mit dem Hyaloplasma um den Kern herum besonders zusammengedrängt. Der gleiche Vorgang spielt sich dann an den Sphären ab, sobald diese zur Einleitung der Zelldurchschnürung (gleichfalls durch Flüssigkeitsentziehung; cf. Rircmuster, 96) verdichtend auf das ungebende Protoplasma wirken. So entsteht die hantelförmige Umkleidung der Kernhantel (Fig. 3).

Der Zug der Sphären bewirkt dann zur Zeit der Zelldurehsclinuirung ein Austreten von Kernsaft in das umgebende Hyalo-

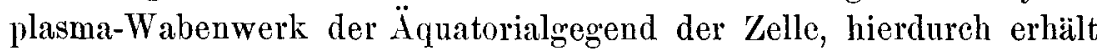
das Hyaloplasma ein weniger dichtes Gefüge als vorher und die Körnchenzusammenhäufung verschwindet in diesem äquatorialen Gebiet, das wir im Vergleich mit Bürschli's Gelatinespindeln nach dem Lichterwerden als BüTscHLI'schen Raum bezeichnet haben (Fig. 8 und 9).

Nach der Zelltrennung hört jede Lokalverdichtung des Protoplasmas auf; das Hyaloplasma vertheilt sich (wie ich früher gezeigt habe, auf rein physikalische Weise) wieder allwärts in der Zelle; und seine gleichmäßige Vertheilung hebt natürlich auch jede besondere Zusammenhäufung der von ihm passiv mitgeführten Fiscrielschen Kürnchen wieder auf; denn es nimmt bei seiner Vertheilung innerhalb der Zelle auch die Körnchen wieder mit (Fig. 5).

So erscheint und versehwindet die centrale Anordnung der Kürnchen gleichzeitig mit der Plasmastrahlung", wie 
Fischer (99, pag. 501 zu 502) hervorhebt; denn auch die Plasmastrahlung ist nur die direkte mechanische Folge der lokalen Protoplasmaverdichtungen, welche durch die Zusammenhäufung der Körnchen eincn dentlichen Ausdruck erhalten.

Man könnte vielleicht deuken, dass die Zusammenhänfung der Körnchen eine zu hochgradige sei, um allein, wie es hier geschehen ist, der Protoplasmaverdichtung um Kern und Sphären herum zugeschrieben werden zu künnen.

Solchen Zweifeln wird die direkt nachfolgende Arbeit entgegentreten, welche zeigen wird, dass schon ganz geringgradige Protoplasmaverdichtungen ausreichen, $\mathrm{mm}$ eine bildlich recht wirksame Zusammenscharung von kleinen, durch Fïrbung hervortretenden Körnchen imnerhalb des verdichteten Hyaloplasmageriistes hervorzurufen.

Es mag hier noch, um eine weitere Briicke zur folgenden Arbeit zu schlagen, erwähnt werden, dass auch die Pigmentköruchen im Ei von Rana fusca, wie konservirte Schnitte zeigen, sich ganz so zu verhalten scheinen, wie die Fiscrnts'schen Körnchen in Echinidenei. Sie finden sich bekanntlich zu Begimn der Cytokinese nm den Kern herum besonders musammengehäuft. Dass sie in die Kerne selbst eintreten und sich damn unter abermaligem Anstritt in dem Bütschut'schen Raum vertheilen, wie das von Zimnermavs für die spüteren Pigmentzellen angegeben wird, kaun ich bei den Furchungszellen an meinen Prijparaten nicht wahrnehmen. Bezweiteln will ich es nicht. Im Gegentheil hat für mich ein solches Verhalten besonderes Interesse, da es den von mir hehaupteten und mechanisch erklärten Fliissigkeitseintritt und -Austritt aus dem Kern ad oculos demonstrirt. Welcher Fliissigkeitsbewegung sich die Körnchen anschließen, das hängt eben ganz davon ab, zu welcher Flïssigkeit sie die größte Adhäsion besitzen; und ihre Adhïsionsverhältnisse können in anderen etwa späteren Zellen leicht so umschlagen, dass sie sich dann der Bewegung einer anderen Flissigkeit anschließen.

Gättingen, zoologisch-zontomisches Iustitut, 19. Mrürz 1999. 


\section{Litteraturverzeichnis.}

B̈̈тschl, 0, Über die kïnstiche Nachahmung der karyokinetischen Figur. Verhandl. Ver. Heidelberg. N. F. Bd. 5. 1593. pag. 28-41.

Derselbe. Untersuchangen über Strukturen, insbesondere über Strukturen nichtzelliger Erzeugnisse des Organismus und über ihre Beziehungen zu Strukturen, welche außerhalb des Organismus entstehen. Dazu ein Atlas mit Mikrophotographien. Leipzig 1898.

Fischel, A., Über vitale Färbung von Echinodermeneiern wïhrend ibrer Entwickelung. Anatom. Hefte (von Merkel u. Bonnet). 1. Abth. Bd. 11. 1899. pag. 463-505. Taf. $24 / 25$.

Herbst, C., Experimentelle Untersuchungen über den Einfluss der veränderten chemischen Zusammensetzung des umgebenden Mediums auf die Entwickelung der Thiere. Archiv f. Entwickelungsmech. Bd. II. 1896. pag. 455-516. Taf. $26-29$.

Derselbe, Über die zur Entwickelung der Seeigellarven notlwendigen anorganischen Stoffe, ihre Rolle und ihre Vertretbarkeit. I. Theil. Die zur Entwickelung nothwendigen anorganischen Stoffe. Archir f. Entwickelungsmechanik. Bd. V. 1897. pag. 649-793. Taf. 12-14.

Derselbe. Über zwei Fehlerquellen beim Nachweis der Unentbehrlichkeit von Phosphor und Eisen fur die Entwickelung der Seeigellarven. Arehiv f. Eutwickelungsmech. Bd. VII. 1898. pag. 456-510.

Rhlmbler, L, Versuch einer mechanischen Erkliirmng der indirekten Zell- und Kerntheilung. I. Theil. Die Cytokinese. Archiv f. Entwickelungsmech. Bd. III. 1596. pag. 52 - -623. 39 Textfig. u. Taf. 26.

Derselbe, Stemmen die Strahlen der Astrosphäre oder ziehen sie? Archiv f. Entwickelungsmech. Bd. IY. 1897. pag. 657-730. 27 'Textfig. u. Taf. 28.

Derselbe, Zellleib-, Schalen- und Kern-Verschmelzungen bei den Rhizopoden und deren wahrscheinliche Beziehungen zu phylogenetischen Vorstufen der Metazö̈nbefruchtung. Biolog. Centralbl. Bd. 18. 1598. Nr. $1 \mathrm{ff} . \ldots$. . a.

Derselbe, Physikalische Analyse von Lebınserscheinungen der Zelle. I. Bewegung, Nahrungsaufnahme, Defäkation, Vacuolenpulsation und Gehäuseban bei lobosen Rhizopoden. Archiv f. Entwickelungsmech. Bd. VII. 1898. pay. 103-350. 100 Textfig. u. Taf. 6 u. $7 \ldots \ldots$ b.

Dersilbe, Die Mechanik der Zolldurehschnärung nach Mpyss' und nach weiner Auffassung. Archiv f. Entwickelungsmech. Bd. VII. pag. 53j-556. 1898. 5 Textfig. u. Taf. 12 . . . . . c.

Derselbe, Die Furchung des Ctenophoreneies (nach ZIEaler) und deren Mechanik. Archiv f. Entwickelungsmech. Bd. VIII. 1899. pag. 18i-238.

Roux ,W., Fiir unser Programm und seine Verwirklichung. Archiv f. Entwickelungsmechanik. 1s97. Bd. V. Heft 1. pag. 1-80. Heft 2, pag. 219-243.

Zimmermax, K. W., Über die Theilung der Pigmentzellen, speciell der veraistelten intraepithelialen. Archiv f. mikr. Anat. Bd. 36. pag. 404-410. Taf. 15.

Derselbe, Studien ïber Pigmentzellen. Archiv f. mikr. Anat. B1.41. pag. $36 \pi$ -359 . Taf. $23-24$. 
62 L. Rhumbler, Physikalische Analyse von Lebenserscheinungen der Zelle. II.

\section{Inhaltsübersicht.}

A. Fischel's Befunde . . . . . . . . . . . . . . . . 32

B. Erklärang der Fisches'schen Befunde nach meiner 'Theorie. . . . . 34

1. Warum sammeln sich die Fiscrrel'schen Körnchen zu Beginn der Cytokinese um den Kern herum an? . . . . . . . . . . . . . . 35

a. Beruht die Zusammenscharung der Körnchen auf aktiver Wanderung? . . . . . . . . . . . . . . 35

«. Beruht die Bewegung der Kürnchen auf ${ }^{\text {Brown'seher }}$ Molekularbewegung ? . . . . . . . . . . . . . 36

3. Beruht die Bewegung der Fischelischen Kürnchen auf chemotaktischen Vorgängen? . . . . . . . . . . $3 i$

b. Beruht die Zusammenscharung der Kürnchen auf passiver Verlagerung?. . . . . . . . . . . . . . . . . . 38 a. Substanzverschiebungen im Protoplasma während der Cytokinese. . . . . . . . . . . . . . . . . . . 39

c. Beantwortung der ersten Frage nach den Ursachen der Kürnchenzusammenscharung. . . . . . . . . . . . 45 «. Übereinstimwang der gegebenen Erklärung mit Fischus's Bismarckluraun-Färbungen und eventuelle Übereinstimuung mit Bürscull's Versuchen an Gelatinestrahlungen . . . . 46

II. Warum riicken die Kürnchen bei der Bildung der Zellscheidewand aus der Spindelïquatorebene ab? Bürschuı's Gelatinespindeln . 47

a. Warum erscheint die Körnchenabrückung manchmal auf der mit der Einschnürung sümuigen Seite der Zelle zuerst? . . . 51

III. Warum vertheilen sich die FrscInL'schen Körnchen beim Übertritt in das Ruhestadinm wieder allwärts in dor Zelle? . . . . . . . 5t

IV. Einige Bemerkungen iil)er die Aufnalime der Farbstoffe von außen 55

V. Zusammenfassung . . . . . . . . . . . . . . . . 56

Litteraturverzeichnis . . . . . . . . . . . . . . . . . 61 